\title{
Decrease of histamine induced bronchoconstriction by caffeine in mild asthma
}

\author{
J C Henderson, F O'Connell, R W Fuller
}

\begin{abstract}
Background-While high doses of caffeine may affect pulmonary function and bronchial challenge tests in patients with mild asthma, the effects of lower doses ( $\leqslant 5 \mathrm{mg} / \mathrm{kg}$ ) are less well documented. Specific recommendations exist for withholding theophylline, but not caffeine, before bronchoprovocation and pulmonary function testing.

Methods-To assess the effect of a single oral dose of caffeine $\left(5 \mathrm{mg} / \mathrm{kg}\right.$ ) on $\mathrm{FEV}_{1}$ and bronchial responsiveness to histamine a double blind, placebo controlled study was performed in eight patients with mild stable asthma.

Results-While caffeine had no effect on $\mathrm{FEV}_{1}$, mean (95\% confidence interval) $\log \mathbf{P C}_{20}$ histamine was significantly higher 150 minutes [caffeine $=0.99(0.2)$ $\mathrm{mg} / \mathrm{ml}$, placebo $=0.53(0.29)]$ and 240 minutes [caffeine $=0.89(0.24)$, placebo $=$ $0.44(0.26)]$ after administration of caffeine than after placebo.

Conclusions-Caffeine should be excluded from the diet for a period of more than four hours before bronchial provocation testing. The exact length of time for which it must be excluded requires further study.
\end{abstract}

(Thorax 1993;48:824-826)

Caffeine is a methylxanthine commonly consumed in coffee, tea, chocolate, and some carbonated beverages. Theophylline, a closely related compound, is an effective bronchodilator and may attenuate bronchoconstriction induced by various challenge agents. ${ }^{1}$ It is unclear, however, whether caffeine has these properties. An inverse correlation between caffeine intake and the prevalence of asthma has been reported. ${ }^{2}$ Several studies have shown that caffeine may improve forced expiratory volume in one second $\left(\mathrm{FEV}_{1}\right)$, forced expired flow at $25-75 \%$ of vital capacity $\left(\mathrm{FEF}_{25-75}\right)$ and specific airways conductance (sGaw), and protect against bronchoconstriction induced by exercise and dry gas hyperventilation. ${ }^{3-8}$ However, in these studies high doses $(7-10 \mathrm{mg} / \mathrm{kg}$ ) of caffeine were used or the study patients had moderate to severe asthma and therefore presumably had high resting bronchial tone. The effects of lower doses of caffeine (equivalent to normal dietary caffeine intake) in mild asthma are less well documented although two studies have shown no effect of 5-6 $\mathrm{mg} / \mathrm{kg}$ on pulmonary function and bronchial reactivity to inhaled histamine and carbachol..$^{910}$ Some authors have therefore suggested that withdrawal of caffeine from the diet before bronchial challenge or pulmonary function testing is not necessary. ${ }^{10}$ While specific recommendations exist for withholding theophylline before bronchoprovocation and pulmonary function testing, ${ }^{11}$ no such recommendations exist for caffeine.

The objective of this study was to examine the effect of a dose of caffeine equivalent to three cups of coffee $(5 \mathrm{mg} / \mathrm{kg})$ on $\mathrm{FEV}_{1}$ and bronchial reactivity to histamine. This dose was chosen as only $19 \%$ of the population have more than three cups of coffee per day. ${ }^{27}$ Caffeine reaches peak plasma levels at approximately one hour ${ }^{6}$ and, in previous studies where a bronchodilator effect was seen, the maximal response was at two hours. ${ }^{67} \mathrm{We}$ therefore studied the effects of caffeine over four hours.

\section{Methods}

A double blind, randomised, crossover trial was carried out in eight (four women) stable mild asthmatic patients with a provocative concentration of histamine causing a $20 \%$ fall in $\mathrm{FEV}_{1}\left(\mathrm{PC}_{20}\right.$ histamine) of less than 8 I $\mathrm{mg} / \mathrm{ml}$ (range $1.36-5.73 \mathrm{mg} / \mathrm{ml}$ ) and a mean age of 30 (range 21-44) years. Before the $N$ study all subjects used inhaled $\beta_{2}$ agonists as required. None required other medication and all were non-smokers. The study was approved by Hammersmith and Queen Charlotte's hospitals' research ethics committee and all subjects gave written informed consent.

Subjects attended on two separate study days at least one week apart but within two weeks of each other. They refrained from taking caffeine containing products for 48 hours and $\beta$ agonists for 10 hours, and fasted for eight hours before each study period. On each study day $\mathrm{FEV}_{1}$ and $\mathrm{PC}_{20}$ histamine were measured 30 minutes before and 60 , 150, and 240 minutes after ingestion of caffeine or matched placebo (prepared by Nicholas Laboratories Ltd, UK).

Histamine diphosphate (Sigma, UK) was dissolved in normal saline to make doubling 
concentrations from 0.5 to $32 \mathrm{mg} / \mathrm{ml}$. $\mathrm{FEV}_{1}$ (best of three values) was measured with a dry spirometer (Vitalograph Ltd, UK). ${ }^{12}$ From just below functional residual capacity the subjects then inhaled five breaths of normal saline from a Nebicheck nebuliser attached to a dosimeter (PK Morgan Ltd, UK) with a five second breath hold after each inhalation. $\mathrm{FEV}_{1}$ was measured one minute after the last breath. Subjects then inhaled, in the same fashion, five breaths of doubling concentrations of histamine with measurement of $\mathrm{FEV}_{1}$ one minute after the last dose. The challenge was stopped when a $20 \%$ fall in $\mathrm{FEV}_{1}$ had been achieved or the highest concentration of histamine had been administered. The provocative concentration of histamine which would have caused a $20 \%$ fall in $\mathrm{FEV}_{1}$ compared with saline $\left(\mathrm{PC}_{20}\right)$ was calculated by interpolation from the log concentration-response curve. ${ }^{11}$

\section{STATISTICAL ANALYSIS}

$\mathrm{FEV}_{1}$ values were compared between the two study days by one way analysis of variance (ANOVA). For each subject the change in $\log \mathrm{PC}_{20}$ from baseline was calculated. Comparisons were then made between the two treatments by two way ANOVA and multiple range testing.

\section{Results}

Baseline mean $(95 \% \mathrm{CI}) \mathrm{FEV}_{1}$ values were $91 \%(10 \cdot 8 \%)$ of predicted $^{12}$ on the placebo study day and $91 \%(9 \cdot 2 \%)$ on the caffeine study day. $\mathrm{FEV}_{1}$ did not change significantly after administration of caffeine or placebo and there was no difference between the two treatments. Baseline mean $(95 \% \mathrm{CI}) \log \mathrm{PC}_{20}$ was $0.54(0.16) \mathrm{mg} / \mathrm{ml}$ on the placebo study day and $0.63(0.15) \mathrm{mg} / \mathrm{ml}$ on the caffeine study day. $\log \mathrm{PC}_{20}$ values (change from baseline) were significantly higher 150 and 240 minutes, but not 60 minutes, after caffeine compared with placebo ( $p<0.001$, fig). The protective effect of caffeine compared with placebo 150 and 240 minutes after administration was equivalent to $1.54(0.59)$ and $1.48(0.83)$ doubling dilutions of histamine respectively.
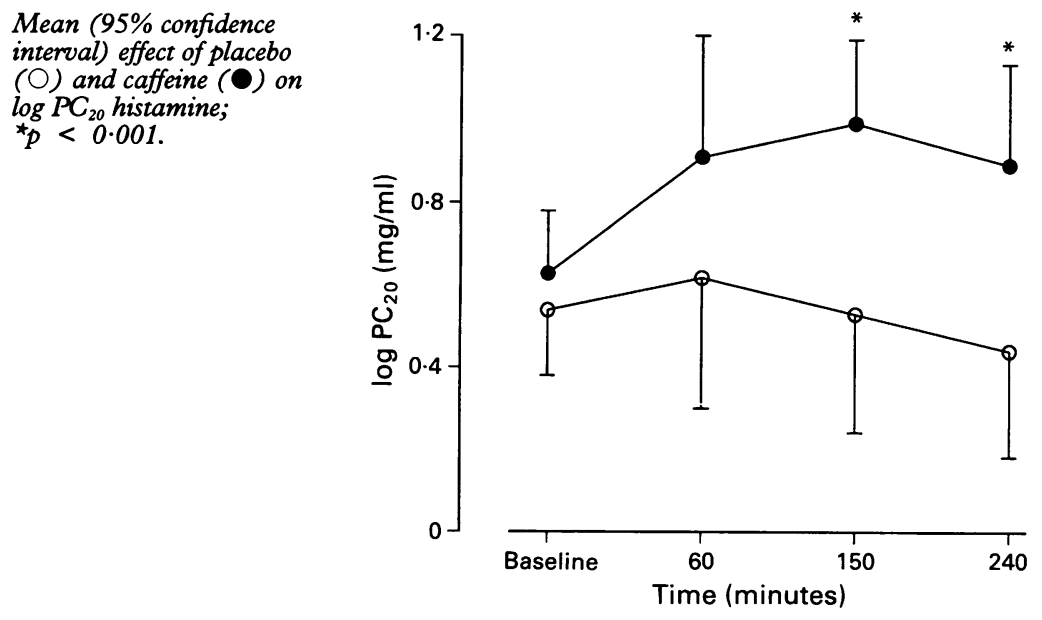

\section{Discussion}

We have shown that, in mild asthma, caffeine at a dose equivalent to three cups of coffee reduces the response to histamine but does not affect $\mathrm{FEV}_{1}$. The effect occurred after 60 minutes, was maximal at 150 minutes, and still present at 240 minutes. This differential effect on bronchial responsiveness to histamine without an effect on prechallenge $\mathrm{FEV}_{1}$ is probably due to the mild nature of the disease in the patients we studied. Baseline mean $\mathrm{FEV}_{1}$ was $91 \%$ of predicted on both study days. Caffeine did not have an effect on resting bronchial tone which was low, but protected against the increase in bronchial tone induced by histamine. The lack of a bronchodilator effect of caffeine is consistent with two previous studies in mild asthma. ${ }^{910}$ However, in other studies in patients with moderate to severe asthma improvements in $\mathrm{FEV}_{1}, \mathrm{FEF}_{25-75}$ and sGaw have been seen. ${ }^{5-8}$ Higher doses of caffeine have also been shown to have a bronchodilator effect in patients with mild asthma. ${ }^{34}$ In addition, caffeine has been shown to have a protective effect against dry gas hyperventilation ${ }^{4}$ and exercise challenges ${ }^{3}$ in patients with mild asthma, but only with higher doses than we have used ( 10 and $7 \mathrm{mg} / \mathrm{kg}$ ).

In a recently published study the same dose of caffeine which we have used had no effect on bronchial reactivity to inhaled histamine in 10 subjects with mild asthma and the authors suggested that omission of caffeine from the diet was not necessary before bronchial challenge testing. ${ }^{10}$ However, histamine challenge was performed 120 minutes after administration of caffeine in that study and the protective effect was not seen until 150 minutes in our study, so it may have been missed. Our study clearly shows that even low doses of caffeine may afford protection against histamine bronchial challenge in mild asthma, and previous studies have shown that low doses afford protection against bronchial challenge and even have a bronchodilator effect in moderate to severe asthma. We therefore recommend that caffeine should be withdrawn from the diet for a period of more than four hours before all pulmonary function and bronchial challenge testing. Further studies may elucidate the exact length of time for which caffeine withdrawal is necessary. For the purposes of routine spirometry in normal subjects or patients with mild asthma, failure to abstain from caffeine is unlikely to affect results significantly.

1 Magnussen H, Refuss G, Jorres R. Theophylline has a dose-related effect on the airway response to inhaled histamine and methacholine in asthmatics. Am Rev Respir Dis 1987;136:1163-7.

2 Pagano $R$, Negri E, Decarli A, La Vecchia C. Coffee drinking and prevalence of bronchial asthma. Chest 1988;94:387-9.

3 Kivity S, Aharon YB, Man A, Topilsky $M$. The effect of caffeine on exercise-induced bronchoconstriction. Chest 1990;97:1083-5. 
4 Duffy P, Phillips YY. Caffeine consumption decreases the response to bronchoprovocation challenge with dry gas hyperventilation. Chest 1991;99:1374-7.

5 Bukowskyi M, Nakatsu K. The bronchodilator effect of caffeine in adult asthmatics. Am Rev Respir Dis 1987;135:173-5.

6 Becker AB, Simons KJ, Gillespie CA, Simons FER. The bronchodilator effect and pharmacokinetics of caffeine in asthma. N Engl f Med 1984;310:743-6.

7 Gong H, Simmons MS, Tashkin DP, Hui KK, Lee EY Bronchodilator effects of caffeine in coffee: a doseresponse study of asthmatic subjects. Chest 1986;89. 335-42.

8 Simmons $M$, Gong $H$, Tashkin DP, Hui $K$, Lee $E$.
Bronchodilator effects of coffee in asthmatics. Chest 1983;84:332.

9 Crivelli M, Wahllander A, Jost G, Preisig R, Bachofen H. Effect of dietary caffeine on airway reactivity in asthma. Respiration 1986;50:258-64.

10 Colacone A, Bertolo L, Wolkove N, Cohen C, Kreisman $\mathrm{H}$. Effect of caffeine on histamine bronchoprovocation in asthma. Thorax 1990;45:630-2.

11 SEPCR Working Group on Bronchial Hyperreactivity. Guidelines for standardisation of bronchial challenge with (nonspecific) bronchoconstricting agents. Bull Eur Physiopathol Respir 1983;19:495-514.

12 Quanjer PhH. Standardization of lung function tests. Bull Eur Physiopathol Respir 1983;19(suppl 5):7-10.
Someone's advice for success was to put yourself in a position to be lucky, know that you have been lucky, and convince others that you were lucky; this piece is written in that spirit.

My abiding pleasure has been clinical physiology and, in particular, the physiology of exercise. In 1962, at a time when my interest was germinating as a raw registrar at the Hammersmith, the Wellcome Trust gave me the opportunity to go to Scandinavia where the best work was being done and where departments of clinical physiology were thriving. In Copenhagen, Dr Erling Asmussen received me with fatherly patience and courtesy in showing me his Rehabilitation Institute, and I watched spellbound while he carried out an experiment with Marius Neilsen and Mogens Jorgensen on the effects of partial curarisation on exercise ventilation in a normal volunteer. Asmussen had published continuously since the mid 1930 s with Neilsen, and I still refer to his chapter in the Handbook of Physiology. Across the Kattegat in Göteborg, Erik Berglund took me round the Renströmska Sjukhuset where Gösta Birath was Head, and the Sahlgrenska which housed the University's Department of Clinical Physiology. He showed me the results of a population study to establish normal standards for spirometry which remains for me the best study of its kind. Jan Bjure shared the results of his studies of carbon monoxide uptake in exercise, and Bror Söderholm talked at length on the value of exercise testing in cardiac disorders; Gunnar Grimby challenged my classical views on exercise limitation. The organisation and work of the Department of Clinical Physiology was an eye opener, and on the first of several occasions I was put on a cycle ergometer and pedalled my best for Queen and country. A flight north almost to the Arctic Circle ended in a nail biting landing in thick fog at Umeå, happily on the eve of the first day of spring with its serious celebra- tions. Another of the pioneer clinical exercise physiologists, Håkan Linderholm, was my host and head of the department. On the holiday a family outing to see his ancient yawl ended sadly, for the thaw had come and only the tops of the masts were visible. At the new medical school the department was young, well trained and enthusiastic. Gunther Koch and Torsten Ringquist tolerated my ignorance with good humour. Torsten introduced me to his thesis work on respiratory muscle strength; a member of the Swedish cross country skiing team, he was to die tragically young of an acute cardiomyopathy. Back south in Stockholm Per-Olof Asstrand, then as now the doyen of exercise physiologists, picked me up in his battered Volkswagen and took me to the Central Gymnastic Institute where I saw Björn Ekblom measuring maximum oxygen uptake in a child skiier and Bengt Saltin took me through studies of acclimatisation to heat and exercise. A visit to $\mathrm{Dr}$ Bjurstedt's Institute of Aviation Physiology introduced me to the new technology of breath by breath measurements of gas exchange and online continuous blood gas measurements. My trip ended with a visit to $\delta$ Alf Holmgren at the Karolinska Institute and a view of all the information to be gained from exercise in cardiac patients.

I hope I have convinced the reader that I $\frac{D}{2}$ was lucky; this has been something of a belated "thank you" to these brilliant os Scandinavians, not only from me but on $\stackrel{0}{0}$ behalf of all of us who followed in their foot- $N$ steps in using exercise as a clinical tool. It has also reminded me of certain qualities of academic life which I hope still endure even in $\mathbb{D}$ today's all too competitive environment - the fascination and rewards of clinical physiology; the generosity and camaraderie of scientists; the value of a few days spent in another laboratory; and the importance of encouragement in helping young investigators to start on their careers. 